\section{Particle Accelerator Conference \\ Sheraton Palace Hotel, San Francisco, California \\ May 6-9, 1991}

\title{
Magnetic Properties of Iron Yoke Laminations for SSC Dipole Magnets*
}

\author{
S.A. Kahn and G.H. Morgan \\ Accelerator Derelopment Department \\ Brookhaven National Laboratory, Upton, NY 11973
}

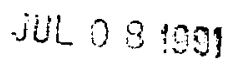

\section{ABSTRACT}

We examine the magnetic properties for the iron used in the SSC yoke leminations so that the acceleretor tolerances can be met. The accelerator requirementa for field quality specify a tolerance on the rariation in the central feld. At machine injection the variation in feld is attributed to coercivity, $B_{e}$. Requirementa on the magnitude and the rariation of $B_{c}$ are presented. At the 6.65 teala operating field the rariation in the anturation magnetiration dominates the magnetic bolerance for the iron.

\section{INTRODUCTION}

$A$ high degree of central field aniformity is required for the SSC main ring dipoles. This requirement it specified by a RMS tolerance in $\frac{A B_{a}}{B_{0}}<0.001$. It is asoumed that a tolerance half of this ralue can be aefely exagned to variations in the iron properties of the yoke. Since iron propertien are independent of magnet conotration errors, these tolerances can be odded in quadrature. Tolerances for Fourier harmonica bigher than the fundumental, $B_{0}$, are not ignificantly influenced by variations is iron properties.

In this study iron properties are examined at low field correoponding to beam injection, at mediem telds with rapid changes in permeabiliky, and at the bigh operating fieldr. At low field the variation is expeeted to be dominated by $\boldsymbol{B}_{c}$ or effects correlated to $B_{c}$ such a the low feld permentility. Low field properties tend to be related to grain aive, work hurdening, etc. The fincl proceaning that is done to the steel has a large efiect on $H_{c}$ as it aleo has on other propertien such as the jield strength of the material. In this report we ouly consider the magnetic propertie of the yole material, however mechanical properties are considered so as not to make inapproprinte specification. The magnetic effeets at high feld are dominated by the iron anturation. The iron anturation is governed by the chemiotry of the irrim. in this report we deacribe the ealealation that have been done to entablinh the desired iror properties for the SSC main ring dipole megnets. A similar type of andycie was performed on the yole steel for ISABELLE magrets."

\section{INJECTION FISD REQUTREMENTS}

At machine injeetion emergy, the main ring dipole pinguets we a feld of 0.66 teala. At injection exrrent the variation in feld is dependent on remmant fielde from previons excitation and deviation in the low feld permenhility of the ateel. Both of these effects are dependent on $\boldsymbol{H}_{c}$. To eatimnte the sire of the seld in the aperture from the remnant field in the jron we can apply Ampere's law to a clowed path through the eperture and around the yole. Figare 1 shows the far lines for the 5 em dipole magnet at injection field. Applying Ampere's law asuming that there is no current in the magnet givet:

$$
B_{o} \times l_{\text {sep }}+H_{\text {irom }} \times l_{\text {irom }}=0
$$

The mean ratio of firas can be determined $\bar{b}_{\mathrm{y}}$ taking the aux everage of the lengths. This ratio is

$$
\left(\frac{l_{\text {iron }}}{l_{\text {lop }}}\right)=1.71
$$

We would expect the rariation, $\Delta B_{\text {, }}$ in the eperture region due to rajetions in $B_{c}$ to be

$$
\Delta H_{c}=\frac{\Delta B_{6}}{1.71}
$$

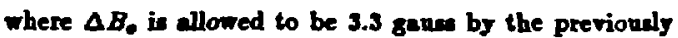
mentioned tolerasce. This provides a rather achienble requirement that $\Delta H_{e}<1.90$.

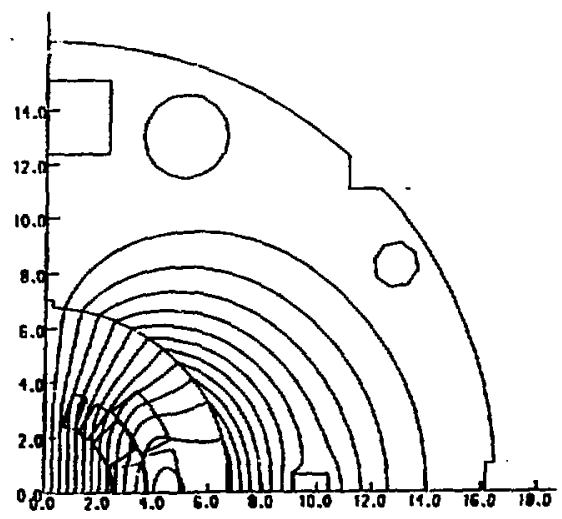

Figure 1: $5 \mathrm{~cm}$ SSC dipole with Iux plot corresponding to injection feld.

A more complete andyit of the low field beharior of this magnet wa performed weing the srite elemeat progran PE2D2 with sormal B-H tables corresponding to $H_{\varepsilon}=0.7 \mathrm{Oe}$ and $1.8 \mathrm{Oe}^{3}$ To imulate the hyoteredis efiet os these carves $H_{c}$ is sabtracted (edded) to each of thewe carver corresponding to the deacending (acending) earve. 
Table 1 gives $B_{0}$ for a current erreep using the 0.7 (1.8) Oe materials. Both the normal curve and the descending curve are shown. (The normal curve is approrimately the average of the ascending and descending curves.) The difference between the normal curve and the descending curve gives $\Delta B_{0}=1.0(0.96)$ gauss for the $H_{c}=0.7(1.8)$ Oe. There is an additional contribution from the change in permeablility that is associated to the change in $H_{c}$. We see a change in $B_{o}$ of 1.87 gauss for a change of $H_{c}$ of 1.1 Oe. As these affects are correlated we add there contributions. Asouming that this difference represente a variation in $B_{o}$, the allowable variation in $H_{\mathrm{c}}$ is estimated to be 1.1 Oe. which is quite large. Figure 2 shows the RMS rariation in $H_{c}$ for steels used in and propowed to be uned in a number of different accelerators verses $H_{e}$. The lower $\boldsymbol{H}_{c}$ steela are final annealed to various extents. The higher $H_{c}$ steels are not annealed. Some of the larger $\Delta H_{c}$ is supposedly due to working of the material to make laminations. It is expected that the variation in $H_{c}$ will not be a problem and that requesting $\Delta H_{c}<0.25$ Oe should be attainable.

Table 1: $B_{0}$ verses I normal and descending curves correaponding to materials with $H_{c}=0.7$ Oe and 1.8 Oe, respectively. The normal curve is the average of the arcending and descending curves.

$\therefore \quad$\begin{tabular}{|r|r|r|r|r|}
\hline Current & Normal & Descend & Normal & Descend \\
ampt & $H_{c}=0.7$ & $H_{c}=0.7$ & $H_{c}=1.8$ & $H_{c}=1.8$ \\
\hline 660 & 6883.8 & 6884.8 & 6881.0 & 6882.9 \\
1000 & 10430.3 & 10431.3 & 10428.0 & 10428.9 \\
2000 & 20859.7 & 20860.7 & 20856.4 & 20857.4 \\
\hline
\end{tabular}

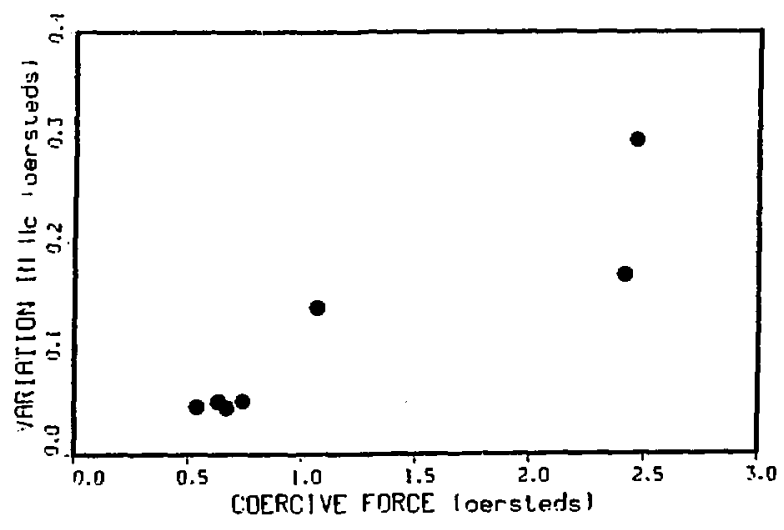

Figure 2: $\Delta H_{c}$ verees $H_{c}$ for different stecls used in eriating and propoeed accelemtors.

The desired mean valne of $\boldsymbol{H}_{c}$ is relected based on the correlation between $\boldsymbol{H}_{c}$ and the permeability, $\mu$. Figure
3 demonstrates this correlation. $H_{c}$ is chosen such that $\mu$ will be greater than 500 gauss/Oe for essentialiy all samples. This procedure indicates that $\left\langle H_{c}\right\rangle$ should be less than 1.8 Oe.

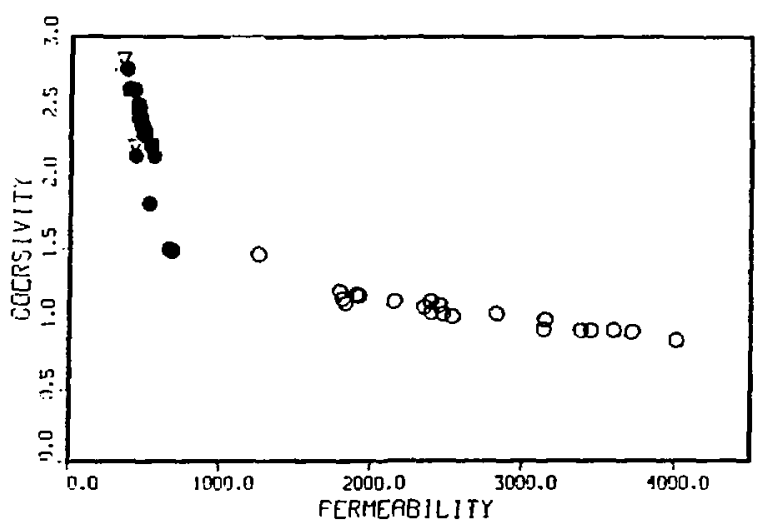

Figure 3: Permeability, $\mu$ verses $H_{c}$ for different steels used in eristing and proposed accelemtors.

\section{OPERATING FIELD REQUIREMENTS}

At high field the variation in field is due to variations in the saturation maguetisation, $\mathbf{M S}_{S}$. To determine the allowable variation in $M_{S}$, different B-H curves are derived conresponding to a known deviation in $M_{S}$. These B-H relations are obtained by using the Frohlich-Kennelly formula,

$$
\frac{H}{B}=a(H)+\frac{B}{M_{S}}
$$

where $\mathrm{a}(\mathrm{B})$ is chowen to be a function of $\mathrm{H}$ so that it corresponds to our standard B-H curre and $M_{S}$ is allowed to vary by a small known amonnt. Table 2 shows $B_{0}$ for various currents correnponding to the standard B-H curve and to curves with $\mathrm{MS}_{S}$ increased and decreased by $78 \mathrm{Oe}$. At 6500 amps we find that with

$$
\alpha=\left(\frac{\Delta B_{0}}{B_{0}}\right)\left(\frac{M_{S}}{\Delta M_{S}}\right)
$$

$\alpha=0.187$ where $\alpha$ depends primarily on the geometry of the yoke. The allowable tolerence permits a RMS $\Delta M_{S}= \pm 57$ Oe.

Measuring $\Delta M_{S}$ to snfficient accuracy to be reeful to monitor the production of the steel in not easy. As $M_{S}$ is primarily dependent on the chemistry of the :teel, monitoring the steel chemistry may be the practical approach. 


\section{INTERMEDIATE FIELD}

In the intermediate field region the permeability varies substantially across the yoke. The attributes that affect the permeability are the chemistry which determines $M_{S}$ and the grain sire, etc. that afiect $H_{c}$ at low field. The Frohlich-Kennelly relation was originally intended to be a phenomenologieal expressioa describing the approsech to saturation where $a(H)$ is generally chosen to be a constant or a low order polynomial in $\frac{1}{H}$. In this application however we are assuming that the entire $B$ range, which is four orders of magnitude, can be deseribed by the relation where $a(B)$ is chosen so that the correet B-H relation holds. Over this range $a(H)$ varies by only a factor of 5 . Although $a(B)$ itself is not a physical quantity, it describes in some sense attributes related to the permeability that are independent of $M_{S}$. In a procedure similar to that which was used for $M_{S}$ we change the B-H curve by varying a(H) by a small amount and using the Frohlich-Kennelly relation to reconstruct the curve. Table 3 shows the results for a variation of $\Delta a= \pm 5 \times 10^{-5}$. Although this chosen variation of $\Delta a$ is considered large it is not nnrepresentative (unfortunately) of what one can obtain. (We received a shipment of steel which appeared to be "mechanically worked" to the extent that the rariation in $a(H)$ was this large.)

Table s: $B_{o}$ verwes I for curves corresponding to the standard $B-H$ curve and to thowe with $\mathbf{a}(B)$ increased or decrease by $5 \times 10^{-5}$.

\begin{tabular}{|c|c|c|c|}
\hline $\begin{array}{c}\text { Current } \\
\text { amps }\end{array}$ & $\begin{array}{c}\text { Standard } \\
\text { Table }\end{array}$ & $\begin{array}{c}\text { Decreased } \\
\mathrm{a}(\mathrm{H})\end{array}$ & $\begin{array}{c}\text { Increased } \\
\mathrm{a}(\mathrm{H})\end{array}$ \\
\hline 660 & 6884 & 6885 & 6883 \\
5000 & 51858 & 51871 & 51846 \\
5500 & 56702 & 56717 & 56687 \\
6000 & 41340 & 61358 & 61323 \\
6500 & 65799 & 65816 & 65781 \\
7000 & 70118 & 70134 & 70101 \\
\hline
\end{tabular}

Table 2 indicates that small effects of the onset of the variation in saturation are present in the intermediate region at 5000 amps. If we asume that the foll allowable tolerance in $M_{S}$ is used at 6500 amps, then $\Delta M_{S}$ at 5000 amps would represent only about $30 \%$ of the tolerance. Since $M_{S}$ and a are presumed nncorrelated, $\Delta a$ can take $95 \%$ of the allowable tolerance implying that $\Delta a<$ $1.0 \times 10^{-4}$ which we believe can be achieved.

\section{REFERENCES}

1. M.J. Tannentaum et al., Magnetic Properties of the Iron Lamination for CBA Magnet, IEEE Transactions on Nuclear Science 30-NS p3472 (1983), BNL report 32711.

2. PE2D is a computer program for the $2 D$ calculation of Poiseon's equation. PE2D Reference Menual, VF088924, Vector Fields Ltd., Oxford, England.
Table 2: $B_{0}$ verses I for curves corresponding to the standard B-H curve and to those with $M_{S}$ increased or decrease by 78 Oe.

\begin{tabular}{|c|c|c|c|}
\hline $\begin{array}{c}\text { Current } \\
\text { amps }\end{array}$ & $\begin{array}{c}\text { Standard } \\
\text { Table }\end{array}$ & $\begin{array}{c}\text { Decreased } \\
M_{S}\end{array}$ & $\begin{array}{c}\text { Increased } \\
M_{S}\end{array}$ \\
\hline 660 & 6884 & 6884 & 6884 \\
5000 & 51858 & 51846 & 51870 \\
5500 & 56702 & 56678 & 56725 \\
6000 & 41340 & 61304 & 61377 \\
6500 & 65799 & 65754 & 65844 \\
7000 & 70118 & 70066 & 70169 \\
\hline
\end{tabular}

3. Data supplied by Armco Inc., Middletown, Ohio..

4. Data for this figure come from iron samples used for ISABELLE, SSC prototypes, FNAL new mainring project, LEP, and HERA. Publiehed references are

- K. Sinram et al, The Infivence of Fine Blanking on the Magnetic Properties of Soft Magnetic Iron, DESY (1990).

- H. Laeger et a, Production of the Soft Magnetic Steel Laminations for the LEP Dipole Magnets, CERN LEP-MA/87-52 (1987).

- Also we would like to thank Armco and LTV for the use of their data.

-Work supported by the U.S. Department of Energy 